\title{
Reconfiguring the Value Chain to Implement Postponed Manufacturing
}

\author{
Remko I. van Hoek \\ Erasmus University Rotterdam, the Netherlands \\ Faculty of Economics/RIBES \\ e-mail: remko.van.hoek@PI.net fax:+31-104526280
}

\begin{abstract}
A move towards the centralization of inventories in European value chains, has been observed over the past years, increasingly companies are adding the application of postponed manufacturing (customization to order) to these centres. A framework for the analyses of reconfiguration patterns in value chains is introduced and used in eight case studies. Results suggest that the implementation of postponed manufacturing requires chain-wide reconfigurations, not limited to logistics systems. Different reconfiguration paths were found (no universal solution). Based on these differences suggestions for implementation paths are developed. Also a model is developed that describes the evolution of warehouses in the chain and that can help understand the regional economic impact of postponed manufacturing.
\end{abstract}

\section{Keywords}

Postponement, implementation, regional economic development

\section{INTRODUCTION}

Companies have been focused on the reconfiguration of European logistics systems for a number of years. One of the most prominent trends in the configuration of European logistics systems has been the centralization of inventories stored in various European countries in European Distribution Centres 
(EDC's) that service multiple European countries from one point (see for theoretical publication Wills et al. 1972, for cases Bagchi and Skjott-Larsen, 1995; O'Laughlin et al. 1993 and a survey CLM, 1995). Lee et al. (1993) suggest that EDC's may increasingly also be used to perform final manufacturing activities such final assembly and configuration aimed at the final customization of products, based on customer orders. Indeed a prominent development in European logistics systems is the recent emergence of form postponement (Cooper, 1993; van Hoek, 1998). Under this system customization of products is performed in the distribution channel. In order to implement this system further chain reconfigurations are needed, on top of the centralization of inventories.

The study of channel configurations and postponement goes back to the 1960s (Bucklin, 1965). Despite academic relevance and operational benefits of postponed manufacturing, the concept has attracted managerial attention only recently. This may be contributed to the lack of knowledge about the implementation of postponement by manufacturers (Droge et al. 1995). In that respect the purpose of this paper is to contribute to the practical knowledge of postponed manufacturing in European chains. The central question is what the contribution of postponed manufacturing is to the reconfiguration tendencies observed in European over the past years; is it the next wave in the changing European distribution channels? The paper reports findings from 8 in-depth case studies of reconfiguration tendencies, as part of overall change management processes in European chains involved in the implementation of postponed manufacturing. The intention is to develop insights in the implementation of postponed manufacturing, relevant to managers considering postponed manufacturing as relevant value chain concept. Insights about the consequences of the implementation of postponed manufacturing for the evolution of distribution centres in the value chain, finally, may be relevant for the economic development of regions in Europe.

\section{THEORETICAL BACKGROUND; THE EMERGENCE OF MASS CUSTOMIZATION}

Multiple publications have pointed at the fundamental move towards mass customization in value chains. Lampel and Mintzberg (1996) for example, point out that chains can be categorized based on the amount of customization versus standardization in the chain. They point at the generic tendencies among companies to move towards the approach of mass customization, in which upstream standardization is combined with downstream customization. Postponed manufacturing is a concept that can help realize this vision by manufacturing standard modules in large scale facilities with customized final assembly and manufacturing in the downstream stage of the chain. Mass scale and efficiency is thus combined with customization and responsiveness to the final customer. 
Indeed, postponed manufacturing is one of the most important method for achieving mass customization, according to Kotha (1995). The postponement applications may not only include postponed final manufacturing, but according to Cooper (1993) also deferred packaging (local packaging operations) and apart from centralized distribution centres, warehouses located next to the factory or decentral in the market (national warehouses) may also exist.

In order to implement postponed manufacturing a reconfiguration of the value chain may however be required. It may be needed to reposition final manufacturing activities downstream, into a distribution centre, alternatively, it may be needed to integrate components manufacturing in large scale facilities. Using the global, international and local level as possible levels of operation four generic tendencies can be found. These are: tendency 1 ; the upstream integration of activities at a global level of operation, tendency 2; the upstream integration of activities at an international level of operation. Tendency 3 involves a downstream positioning of activities from a global to an international level of operation and tendency 4 the downstream positioning of activities from an international to a local level of operating (van Hoek, 1998).

\section{CASE STUDY FINDINGS}

Table 1 summarizes relevant background information about the case studies. Both cases from European companies and American companies operating in Europe are included (all case studies were conducted in Europe). A diverse range of industries are represented, ranging from high end technology intensive telecom device to less (technologically) complex jeans and coat manufacturing, from the young bio-technology industry to more mature wine market, from consumer market software and pharmaceuticals to business-to-business market transport devices. This allows for a broad analysis perspective. A broad perspective on postponement is assured by the variety of postponement applications found among the cases.

Table 2 presents case studies at the vertical bar and activities in the value chain at the horizontal bar, numbers reflect generic reconfiguration tendencies that can be found along the value chain. Sourcing and primary manufacturing in the case of the software manufacturer (case 1) are partly placed downstream to an international level, in Europe, for disks, booklets etc. whereas the basic software codes are still sourced from the home-base. Also the final manufacturing is positioned downstream in the EDC. Inventory remains positioned in the existing EDC and service, sales and distribution are not altered and remain a largely national business. The wine company (case 2) positioned final processing in its international operating base and expanded into international markets resulting in international distribution. The transport equipment company (case 3) positioned inventories of finished goods at an international level prior to positioning the final 
manufacturing downstream and then started centralizing parts inventory from national stocking points into the international postponed manufacturing operation. The telecom manufacturer (case 4) started centralizing almost the entire value chain from its national organizations to an international level, only service, sales and some distribution remained at the national level. Primary manufacturing was increasingly performed in international and global manufacturing centers of excellence and sourcing was increasingly done globally. The pharmaceutical company (case 5) started centralizing inventory and packaging/final-processing internationally and considered an ongoing centralization process for these activities. This is in contrast with the biotechnology (case 6) which placed large parts of its supply downstream in the European operating base. On top of a European base, large markets furthermore required the establishment of national operations engaging in rapid delivery, testing and quality assurance. Both fashion manufacturers (case 7 and 8) considered positioning low and higher value adding final manufacturing activities in a postponed manufacturing operation which involved the downstream positioning of these activities (washing of jeans and labeling of coats) in the value chain.

Table 1 Case studies

\begin{tabular}{|c|c|c|c|}
\hline Case & Indistry & Ilome continent & Postponed activilies \\
\hline 1 & Software & USA & $\begin{array}{l}\text { Assembly of software packages with } \\
\text { specific documentation }\end{array}$ \\
\hline 2 & Wine & Europe & $\begin{array}{l}\text { Blending, mixing, bottling, labeling } \\
\text { and packing of wine }\end{array}$ \\
\hline 3 & $\begin{array}{l}\text { Transport } \\
\text { equipment }\end{array}$ & Europe & $\begin{array}{l}\text { Sizing, assembly of factory } \\
\text { transportation equipment }\end{array}$ \\
\hline 4 & Telecom devices & Europe & $\begin{array}{l}\text { Assembly, quality control, } \\
\text { packaging }\end{array}$ \\
\hline 5 & Pharmaceuticals & $\begin{array}{l}\text { USA (but with a long } \\
\text { European history) }\end{array}$ & Blistering, packaging \\
\hline 6 & Bio-technology & USA & Final processing, packaging \\
\hline 7 & Fashion (Coats) & Europe & Labeling and reconditioning \\
\hline 8 & Fashion (Jeans) & Europe & Washing and labeling \\
\hline
\end{tabular}

In summarizing, case study findings indicate that the upstream positioning of national inventories in European distribution centers has been continuing over the past years. As expected, the implementation of postponed manufacturing is added to these tendencies. It was found however in the case studies, that the implementation of postponed manufacturing does not always involve the downstream positioning of final manufacturing but might also involve the upstream positioning of final manufacturing. In the mean time the repositioning of other activities, including primary manufacturing and sourcing was involved in a number of case studies. Thus, case study findings indicate that the implementation of postponed manufacturing is approached within a different and 
wider value chain reconfiguration perspective than could be expected based on literature. The next section will try to develop a synthesis of findings.

Table 2 Reconfigurations of the value chain involved in the implementation of postponement

\begin{tabular}{|c|c|c|c|c|c|}
\hline Case: & $\begin{array}{l}\text { Sourcing and primary } \\
\text { narmifacturing }\end{array}$ & $\begin{array}{l}\text { Inventory } \\
\text { keeping }\end{array}$ & mantafacturing & $\begin{array}{l}\text { Distri- } \\
\text { bution }\end{array}$ & Sales \\
\hline 1 (Software) & $-/ 3$ & - & 3 & - & - \\
\hline 2 (Wine) & - & - & 3 & 2 & - \\
\hline 3 (Transport) & - & $-/ 2$ & 3 & - & - \\
\hline 4 (Telecom) & $2 / 1$ & 2 & 2 & 2 & - \\
\hline 5 (Pharma) & - & 2 & 2 & - & - \\
\hline 6 (Bio-tech) & - & 3 & 3 & $3 / 4$ & - \\
\hline 7 (Fashion) & - & - & 3 & - & - \\
\hline 8 (Fashion) & - & & 3 & - & - \\
\hline
\end{tabular}

\section{GENERIC EVOLUTION OF VALUE CHAINS AND REGIONAL CONSEQUENCES}

It can be deduced from table 2 that the reconfiguration paths differ between cases. Depending on the starting point of the company, final manufacturing and other activities may be positioned upstream, this path is most relevant for European companies. Companies like cases 4 and 5 , with a heritage of country-wise localized value chains develop through distinct stages of upstream positioning, including the upstream positioning of final manufacturing. American companies on the other hand may have to decentralize their chain and position activities downstream in order to raise responsiveness to European markets. Companies like cases 1 and 6, with a heritage of global integration are more likely to pass through a stage in which initially national inventory and sales operations are established, followed by the centralization of inventories and, finally, the implementation of form postponement. Some cases involve both tendencies (cases 2 and 3).

In this respect there is no such thing as a universal solution for value chain reconfiguration. Because there is no universal solution one of the key challenges facing companies considering the implementation of postponement is "how to get there." In other words: how to structure the reconfiguration process is a key question for management. In looking specifically at the role of postponed manufacturing operations in the plant network, activities performed at plants are an important factor in realizing its contribution to the strategic capabilities such as global efficiency or local responsiveness, fundamental to mass customization strategies. The postponed manufacturing operations, in the case studies presented here, often grew out of a distribution center in the prior stage(s) of the reconfiguration process. The operation expanded its scope of activities from warehousing and distribution into final manufacturing and product customization. 
As a result, the operation could contribute to responsiveness through customization of products and efficiency in sourcing and inventory keeping. Sometimes postponed manufacturing operations even contribute to the enhancement of product knowledge relevant for future product development. The experience from the customization and final manufacturing of products can be used in improving product design and improving customizability. This suggests that, whereas Ferdows (1989) developed a model for the contribution of manufacturing plants to the achievement of international strategic capabilities, an alternative model can be developed for the evolution of distribution centers. Figure 1 uses the distribution centers found in case studies (and used by Cooper, 1993) and the evolution of warehouses as introduced above in developing a model for the evolution of distribution centers, as well as its contribution to regional development based on an extension of economic activities and contribution to global strategies.

Figure 1 Changing roles of distribution centres

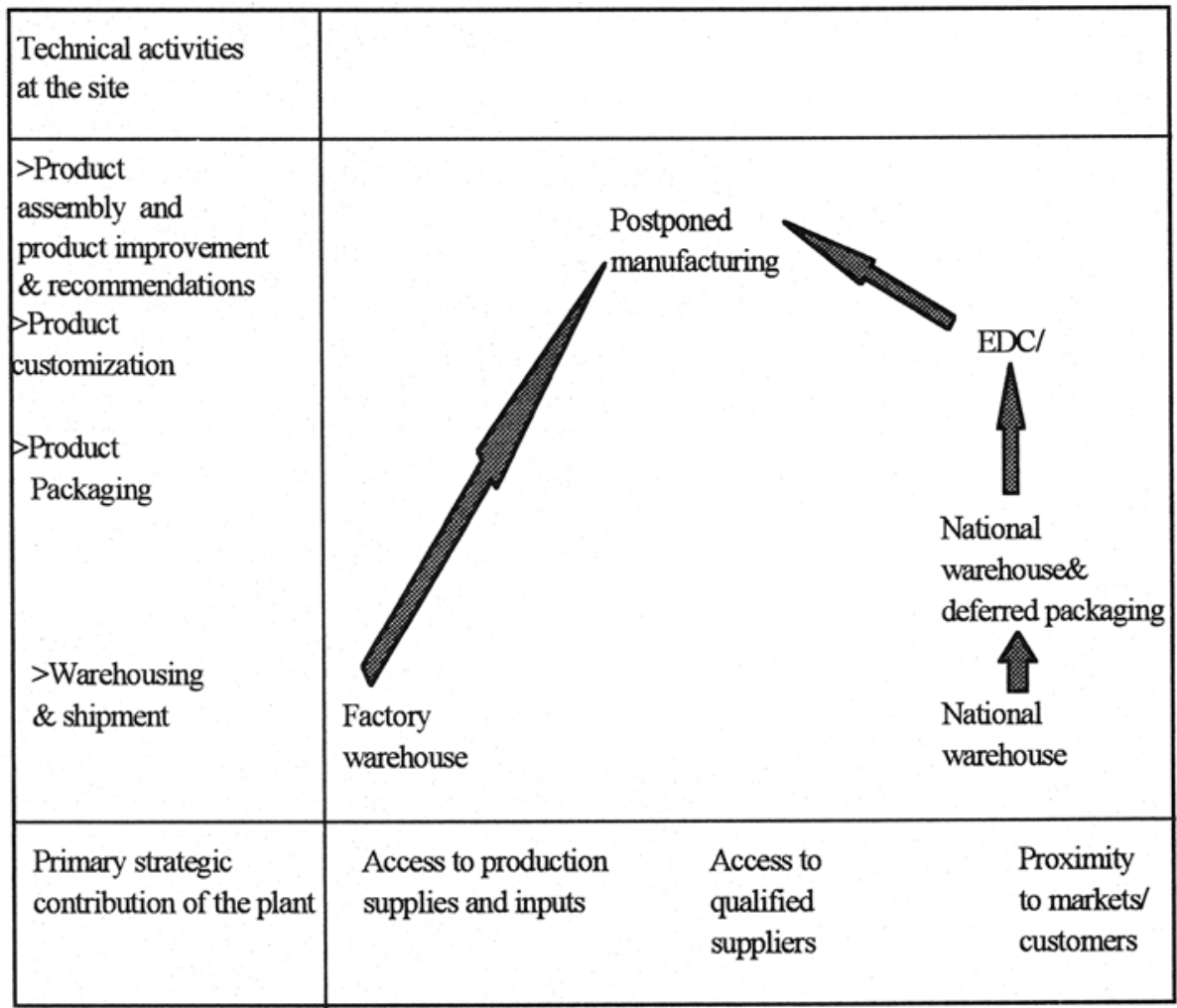


Based on proximity of stocks to local markets national warehouses (right bottom section of the model) contribute to responsiveness. As a next step these centers may start performing simple packaging activities to expand responsiveness beyond distribution service into the packaging and presentation of products. As a next stage, EDC's often develop out of national distribution centers. EDC's then start performing product customization when postponed manufacturing is implemented. Findings from research on factors used for selecting a location for postponed manufacturing applications suggest that access to qualified suppliers is a primary driver of the location of postponed manufacturing operations. This seems logical based on the fact that these operations not only have to source generic modules but also start to perform more technological intensive manufacturing activities.

For factory warehouses, such as those from case 5 (the pharmaceutical company) access to production operations, supplies and inputs is a key factor of the warehousing location. As suggested by Feitzinger and Lee (1997) it may happen that these warehouse operations also develop into postponed manufacturing operations. Either because these can more efficiently perform final manufacturing (Lee et al. 1993) or because primary manufacturing activities are re-located into global manufacturing plants (van Hoek, 1998).

As suggested in figure 1, postponed manufacturing operations may not only have their basis in warehousing and product customization activities but also in a combination of strategically relevant location selection factors. Proximity to markets/customers is relevant for achieving local responsiveness capabilities, access to qualified suppliers is relevant for achieving worldwide learning capabilities and access to supplies and inputs is relevant for achieving global efficiency. The model presented here tends to reflect general reconfiguration tendencies in the distribution channel. Of course the model may be applicable differently depending on the type of distribution center (either coming from left or right/national or factory warehouse). Also the pace of the evolution through the model may differ between companies depending on their organizational heritage. Some companies, finally, may by-pass certain stages by for example creating EDC's right away without having established national warehouses in a prior stage.

\section{DISCUSSION AND CONCLUSIONS}

Postponed manufacturing is a relevant concept for the configuration value chains in diverse cases from various industries studied in this paper. The application of postponed manufacturing followed the introduction of European distribution centers as observed over the past years. In this process companies are actively seeking the realization of a mass customization strategy. 
Apart from the activities involved in the postponement, also the implementation path of postponed manufacturing differs. Lee et al. (1993) suggested that postponed manufacturing may be a resultant of a downstream positioning of final manufacturing activities into the central warehouse/distribution center. It was found that the reconfiguration path of European companies with a long European history may differ in sequence, structure and time-table. Overall, this reflects the role of differences in starting points and heritage between companies.

Based on the revision of the Ferdows (1989) model presented in this paper the role of individual distribution centers/warehouses in the achievement of strategic capabilities based on activities performed and location drivers used can be assessed. A practical implication from this model is that the large number of national warehouses and national packaging operations found in European regions might be sub-optimal when companies progress through the evolution of distribution centers and start further applying postponement. For the managers of these national warehouses the question than becomes which of the regional or national DC's can develop a European scope (EDC) at the expense of other DC's. The model for the evolution of distribution centers presented in this paper indicates that the economic activity in EDC's and postponed manufacturing applications will be concentrated in a limited number of regions by companies that go through the projected evolution.

For regional economies and governments the above implies that the competition among regions for the attraction of these economic activities will increase; no longer will economic activities be duplicated in multiple regions; they will increasingly be concentrated in lead operations located in lead regions. The competition among regions for attracting these operations will not only be based on logistics considerations, as in the creation of EDC's, but also on considerations related to other functional area's, such as manufacturing and sourcing, involved in the implementation of postponed manufacturing. The formation of EDC's, as found so often in European distribution channels, may be a step up to full optimization in modern value chain configurations, using postponed manufacturing. These challenge is not only up to managers to start realizing the benefits of mass customization, but also up to regional and national governments to start targeting postponed manufacturing operations as contributions to economic development, based on the innovative value chain configurations and the manufacturing and logistics activities performed in these operations. Hopefully this paper has provided some useful insights in the strategic considerations and related reconfiguration tendencies found in today's value chains, in order to help both managers and governments in benefiting from the "change in chains." 
Bagchi, P.K. and Skjott-Larsen, Tage (1995) European logistics in transition: Some insights. The International Journal of Logistics Management, vol.6, no.2, p.11-24.

Bowersox, D.J \& Closs, D.J. (1996) Logistical Management, the Integrated Supply Chain Process. Macmillan Publishing Company, New York.

Council of Logistics Management (1995) World class logistics, the challenge of managing continuous change. CLM, Oak Brook.

Cooper, J.C. (1993) Logistics strategies for global business. International Journal of Physical Distribution \& Logistics Management, no.24, p.12-23.

Dröge, C. Germain, R. and Spears, N. (1995) Form postponement as a strategic initiative affecting organizational design, in: Proceedings of the American Marketing Association Summer Educators' Conference, Washington, p.263269.

Feitzinger, E. and Lee, H.L. (1997) Mass Customization at Hewlett Packard, the Impact of Postponement. Harvard Business Review, Jan-Febr. 1997, p.116121.

Ferdows, K. (1989) Mapping international factory networks, in: Ferdows, K. (ed.) (1989) Managing International Manufacturing, Amsterdam, Elsevier Science Publishing, p.3-22.

van Hoek, R.I. (1998) Postponed manufacturing in European supply chain, a traingular approach. KNAG (fax: +31 30 2535523), Utrecht.

Kotha, S. (1995) Mass customization: Implementing the emerging paradigm for competitive advantage. Strategic Management Journal, vol.16, p.21-42.

Lampel, J. and Mintzberg, H. (1996) Customizing customization. Sloan Management Review, Fall, p. 21- 30.

O'Laughlin, K.A. Cooper J. and Cabocel, E. (1993) Reconfiguring European Logistics Systems. CLM, Oak Brook.

Lee, H.L. Billington, C. and Carter, B. (1993) Hewlett-Packard gains control of inventory and service through design for localization. Interfaces, vol.23, no.4, p.1-11.

Wills, G, Magrill, L. and Cooper, A. (1972) The analysis of European distribution systems. International Journal of Physical Distribution, vol.3, autumn, p.2142. 